\title{
Profissão e profissionalização de cuidadores: um estudo a partir dos discursos de sites de empresas especializadas no Brasil
}

\author{
Clara Luisa Oliveira Silva ${ }^{1}$ \\ Instituto Federal de São Paulo (Sorocaba, SP, Brasil)

\begin{abstract}
Alice Gerlane Cardoso da Silva ${ }^{2}$
Universidade Federal de Minas Gerais (Belo Horizonte, MG, Brasil)

José Vitor Palhares ${ }^{3}$

Universidade Federal de Minas Gerais (Belo Horizonte, MG, Brasil)

Kely César Martins de Paiva ${ }^{4}$

Universidade Federal de Minas Gerais (Belo Horizonte, MG, Brasil)
\end{abstract}

No Brasil, a precariedade das políticas públicas voltadas ao cuidado abriu espaço para a privatização e mercantilização do cuidado por meio de planos de saúde e outros tipos de serviços de assistência oferecidos pelas empresas e agências de home care. Mediante esse contexto, o objetivo deste estudo é analisar o discurso empresarial oficial brasileiro sobre o profissional e a profissionalização do cuidador. Para isso, desenvolveu-se um estudo descritivo, de abordagem qualitativa. Os dados foram empreendidos a partir da seleção de discursos apresentados em sites de empresas que oferecem a contratação e/ou indicação dos serviços de cuidador profissional. Para a interpretação do material coletado, utilizou-se o aparato teórico-metodológico de análise do discurso em sua vertente francesa. Dentre os principais resultados, destacamos o discurso da humanização, compromisso e emoções do cuidado propagado pelas empresas em uma tentativa de omitir a relação comercial proveniente da dinâmica dessa ocupação e da precarização das relações de trabalho no âmbito desse mercado.

Palavras-chave: Profissão, Profissionalização, Cuidadores de idosos.

Profession and professionalization of caregivers: a study based on the discourse in websites of specialized companies in Brazil

In Brazil, the precariousness of public policies focused on care made room for the privatization and commodification of care through health plans and other types of assistance services offered by home care companies and agencies. In this context, the objective of this study is to analyze the official Brazilian business discourse about the professional and the professionalization of caregivers. For this, a descriptive study with a qualitative approach was developed. Data were collected through the selection of discourses presented on websites of companies that offer the hiring and/or indication of professional caregiver services. For the interpretation of the collected material, the theoreticalmethodological apparatus of French discourse analysis was used. Among the main results, we highlight the discourse of humanization, commitment and emotions of care propagated by companies in an attempt to omit the commercial relationship arising from the dynamics of this occupation and the precariousness of labor relations within this market.

Keywords: Profession, Professionalization, Caregivers of the elderly.

\footnotetext{
https://orcid.org/0000-0002-3343-6439

https://orcid.org/0000-0002-8084-6019

https://orcid.org/0000-0002-9190-3875

https://orcid.org/0000-0002-5185-9072
} 


\section{Introdução}

profissão do cuidador é uma temática multidisciplinar que atravessa desde as áreas das ACiências da Saúde (Hoffman \& Wallace, 2018), como também a Sociologia (Chen, 2014), a Educação (Quigley \& Hall, 2016) e a Administração (Sotos \& Garcia, 2012). No Brasil, atualmente, a função de cuidador é reconhecida como uma ocupação e envolve cuidar do físico, emocional, psicológico e das necessidades de desenvolvimento de crianças, jovens, adultos e idosos (Lampert et al., 2016). Embora seja pouco valorizado e reconhecido socialmente (Hirata, 2016), o debate em torno da profissionalização e expansão do care ${ }^{5}$ tem crescido mundialmente nos últimos anos (Batista \& Bandeira, 2015), seja devido à demanda por profissionais mais capacitados (Araujo et al., 2017) ou em resposta às novas configurações familiares e demanda de políticas públicas (Guimarães et al., 2011).

Em se tratando do contexto brasileiro, o debate em torno da profissão do cuidador iniciou efetivamente no início da década de 1990, a partir da Política Nacional do Idoso e da Política Nacional de Saúde do Idoso (Batista et al., 2014) e, desde então, diversos atores do cuidado na sociedade - como Estado, mercado, família e instituições filantrópicas - combinam-se de diferentes maneiras de forma a assegurar a organização social do cuidado (Hirata, 2016). Vale destacar que o cuidado era concebido, até certo tempo atrás, como assunto particular das famílias e realizado informalmente, no ambiente doméstico, privado, de forma gratuita. Com o passar dos anos, o cuidado foi se tornando uma questão social e passou a ser assumido pela esfera pública, resultando, dessa forma, em um cuidado formal, domiciliar ou institucional, oferecido tanto pelo Estado quanto pelo mercado (Camarano \& Mello, 2012). Entretanto, há certa precariedade das políticas públicas brasileiras voltadas ao cuidado, marcadas pela pouca atuação do Estado, uma vez que quase não existem políticas e programas de cuidado formal domiciliar no Brasil (Camarano \& Mello, 2010), abrindo espaço, então, para sua privatização e mercantilização (Guimarães, 2016) por meio de planos de saúde e outros tipos de serviços de assistência oferecidos pelas empresas e agências de home care.

Além disso, a profissão do cuidador tem sido destaque mundial devido aos conflitos gerados pela delimitação da atividade de cuidar em cada campo profissional e pelas propostas governamentais de delimitação de sua atuação (Debert \& Oliveira, 2015). Em diversos países, como França, Japão e Brasil, há um significativo número de enfermeiros e auxiliares de enfermagem que são contratados e remunerados como cuidadores (Hirata, 2016), demonstrando que o desenvolvimento de novas profissões pode estar vinculado a disputas jurisdicionais, mas também ao surgimento de formas de simbiose ocupacional (Suddaby \& Muzio, 2015). Esse movimento resultou em conflitos entre cuidadores e os Conselhos Regionais de Enfermagem, os quais alegam que os primeiros infringem o exercício profissional dos enfermeiros e que falta acompanhamento e fiscalização das atividades realizadas pelos mesmos (Duarte, 2006), evidenciando que as profissões estabelecidas podem responder de forma agressiva à expansão de novas ocupações na tentativa de manter o status quo (Bucher et al., 2016). Tal fato destaca também que as diferentes profissões ou grupos ocupacionais são sustentadas por normas e práticas altamente institucionalizadas (Abbott, 1988) e que para novas profissões ou ocupações se estabelecerem é preciso se envolver em dinâmicas de poder sofisticadas (David et al., 2013; Reay et al., 2006).

Cabe ainda ressaltar que cuidador tem sido apontada como a profissão do futuro (Cameron \& Moss, 2007; Maybud, 2015; Smith \& McKie, 2009) e que alguns estudos têm tentado descrever e problematizar os discursos e práticas profissionais que perfazem esses sujeitos, seja na análise de manuais, como a análise do Guia Prático do Cuidador (Araujo et al., 2017) ou

5 Vale ressaltar que o termo care conota um vasto campo de ações e atitudes, tendo em vista as distintas formas de modalidades e nominações do care em diferentes sociedades. Dessa forma, a busca por uma tradução exata do termo reduz diferentes realidades sociais em um mínimo denominador conceitual (Guimarães et al., 2011). Porém, para facilitar a análise e compreensão do tema, neste artigo seguiremos com a proposição de Guimarães et al. (2011) e Sorj (2013), de que, no Brasil, care remete à ideia sobre o trabalho de cuidar e de um conjunto de atividades relacionadas ao cuidado e aos cuidadores. 
de projetos governamentais (Shugrue et al., 2017), o que direciona o desenvolvimento desta pesquisa. Contudo, apesar da importância social da profissão, tal temática é um assunto recente no contexto brasileiro (Debert \& Oliveira, 2015) e não tem recebido a devida atenção no campo da Administração (Flower, 2014; Lampert et al., 2016).

Desse modo, o objetivo deste artigo é analisar o discurso empresarial oficial brasileiro sobre o profissional e a profissionalização do cuidador. Por meio da Análise de Discurso Francesa de 72 sites de empresas e agências que oferecem o serviço de cuidador em todo o Brasil, buscamos compreender como esse profissional é discursivamente apresentado, as práticas evidenciadas para a profissão do cuidado, como esses serviços são ofertados e qual a imagem do profissional que essas empresas almejam passar para o público interessado.

Este artigo está estruturado em cinco seções, a contar desta introdução. Em seguida, delineamos o referencial teórico sobre profissões e profissionalização e sobre a profissionalização da atividade de cuidar de idosos no Brasil, que embasou este estudo. Posteriormente, tecemos os procedimentos metodológicos para a consecução do objetivo proposto. Na quarta seção, analisamos os dados e discutimos os resultados sobre o discurso empresarial oficial brasileiro sobre o profissional e a profissionalização do cuidador. Por fim, apresentamos as considerações finais acerca deste estudo.

\section{Profissões e profissionalização sob o enfoque sociológico: uma breve discussão}

Uma profissão é uma prática social, cuja gênese e continuidade atribuem a fatores ligados à história da humanidade e a modificações cometidas às formas de organização e divisão do trabalho (Nogueira \& Oliveira, 2013). De acordo com Bourdieu (2003, p. 40), "a profissão é uma construção social, produto de todo um trabalho social de construção de um grupo e de uma representação dos grupos, que se insinuou docemente no mundo social". Nesse sentido, o lugar social das profissões permeia o trilho da humanidade e as transformações no mundo do trabalho, ocasionadas pela inerente complexidade da sua divisão social (Nogueira \& Oliveira, 2013).

A sociologia das profissões surgiu como uma abordagem sociológica das ocupações modernas (Santos, 2011) e se preocupa com "a implantação, desenvolvimento, formação e institucionalização das profissões” (Mendonça et al., 2012, p. 394). Constitui um campo da sociologia que incorpora "...um conjunto de abordagens teórico-conceituais que tem como objeto específico a formação e atuação dos grupos profissionais" (Barbosa, 2003, p. 594). Estabelece-se, assim, como um campo consolidado, legítimo, autônomo e claramente delimitado, com autores e teorias próprias, bem como objetos de pesquisa e metodologias (Barbosa, 2003; Santos, 2011).

De modo geral, as profissões são abordadas sob diferentes aspectos nesse campo específico da sociologia, o que decorre da impossibilidade de sistematizar os estudos sob uma única teoria (Weber, 2003). Os distintos modelos teórico-metodológicos que compõem essa área da sociologia recorrem a bases funcionalistas, interacionistas e weberianas (Santos, 2011). Por sua vez, os funcionalistas foram os primeiros a discutir o papel das profissões na sociedade moderna (Moura Jr. \& Helal, 2014). Eles deram ênfase à formação profissional e à construção dos papéis profissionais, valorizando os profissionais na estrutura social (Santos, 2011). Dentre seus principais teóricos merecem destaque Parsons (1939) e Abott (1988). Esses autores estavam preocupados em explicar o que os "profissionais" fazem (Mendonça et al., 2012; Paiva \& Melo, 2008).

Os interacionistas também contribuíram para a sociologia das profissões, principalmente na questão metodológica. Os principais autores dessa abordagem são Hughes e Freidson (Santos, 2011). Hughes versa sobre uma aproximação das profissões com as religiões. Para ele, há profissões que exercem atividades essenciais e outras que desempenham funções auxiliares (Santos, 2011). Já Freidson (1988) reconhece algumas das críticas direcionadas ao profissionalismo e, mesmo assim, o defende como a melhor forma de organizar o trabalho dos 
profissionais. Ele observa as identidades profissionais, estabelecendo discussões por meio das diferenças intraprofissionais (Mendonça et al., 2012; Paiva \& Melo, 2008; Santos, 2011; Weber, 2003).

A abordagem weberiana associa profissões a poder. Os principais autores representantes dessa tradição são: Weber (1999), Johnson (1972) e Larson (1977). Para Weber (1999, p. 91), a profissão era "aquela especificação, especialização e combinação dos serviços de uma pessoa que, para esta, constituem o fundamento de uma possibilidade contínua de abastecimento ou aquisição". Johnson (1972) é considerado um dos discípulos de Weber sobre o tema. Ele aborda a variável do poder e acentua que uma profissão não é ocupação em si, mas uma maneira de exercer controle sobre ela (Mendonça et al., 2012; Paiva \& Melo, 2008; Santos, 2011). Outra autora que iniciou seus estudos a partir da perspectiva weberiana foi Larson (1977). Para ela, as profissões são "uma forma de organização da desigualdade social nas sociedades modernas e de imposição da perspectiva dos grupos dominantes sobre os demais grupos profissionais" (Santos, 2011, p. 32).

Diante desse contexto, percebe-se que não há como discorrer sobre profissões e não considerar as contribuições dos referidos autores. Nesse ponto, a fim de dar continuidade à discussão, convém esclarecer o conceito de profissão que norteará esse estudo. Logo, entende-se por profissão

o conjunto de atividades produtivas desenvolvidas por um grupo de pessoas que possuem conhecimentos específicos, validados academicamente e reconhecidos socialmente, mediante instrumentos regulatórios formais ou informais que são compartilhados coletivamente, garantindo elevado grau de autonomia no exercício de suas atribuições, movidas em certo nível por altruísmo (Paiva \& Melo, 2008, p. 355).

A profissionalização, por sua vez, é o termo usado para descrever um grupo ocupacional que alcançou o status profissional, ou seja, é um processo de reconhecimento social de uma atividade ou ocupação (Maestripieri, 2016; Weber, 2003). Para Abbott (1988), o processo de profissionalização se dá com o desenvolvimento de atividades profissionais baseadas na obtenção de uma jurisdição sobre uma área específica de conhecimento, que pode ser regulada e protegida. Sendo assim, é possível admitir que a questão da profissionalização seja entendida como um

processo que transforma uma atividade desenvolvida no mundo do trabalho mediante a circunscrição de um domínio de conhecimentos e competências específicos, como processo que, calcado nas características de profissões estabelecidas (as profissões liberais), nomeia, classifica uma ocupação como profissão, associando-lhe imagens, representações, expectativas historicamente definidas (Weber, 2003, p. 1127).

Dessa forma, o profissionalismo é reconhecido a partir do momento em que um grupo organizado de trabalhadores obtém o poder de determinar quem pode acessar a profissão, impede outras pessoas de realizar atividades semelhantes e controla os parâmetros de medição de um bom trabalho (Freidson, 2001). Corroborando com essa ideia, Nascimento (2007) salienta que o profissionalismo consiste no processo social desenvolvido pelos praticantes de uma ocupação em busca de legitimidade perante a sociedade para realizar com certa exclusividade as atividades ocupacionais que desenvolvem (Nascimento, 2007).

Cabe ressaltar que as profissões se diferem das ocupações. Existem alguns atributos das profissões que as tornam diferentes das ocupações, como é o caso do atributo da autonomia, enquanto direito de regular e controlar sua própria atividade, e do monopólio profissional, resultado de leis que impedem a competição entre indivíduos não pertencentes a determinado grupo profissional e seus profissionais (Gyarmaty, 1975). A ocupação se expressa nas variadas atividades do mundo do trabalho, enquanto a profissão seria um tipo especial de ocupação, caracterizada pelo domínio de um certo conhecimento formal e pelo controle de instituições de interesse coletivo (associações, conselhos, sindicatos etc.) e outros atores do mercado de trabalho (Pereira-Neto, 1995; Paiva \& Melo, 2008). Nesse sentido, as ocupações que se tornaram 
"profissões" trilharam um caminho padronizado composto de sucessivas etapas de "profissionalização" (Diniz, 2001).

Essas etapas compõem um modelo padrão, que foi elaborado por estudiosos pertencentes às tradições do funcionalismo e do weberianismo, pelo qual uma profissão atinge esse status (Maestripieri, 2016; Neal \& Morgan, 2000). Da mesma forma, Abbott (1988) destaca que o processo de profissionalização geralmente segue um padrão comum para todas as profissões, embora possa haver diferenças relacionadas ao tempo. Segundo Wilensky (1964) e Rodrigues (2002), a constituição das profissões decorreria da: especialização de serviços, criação de associações profissionais, de escolas e universidades para fornecer treinamento orientado e específico para praticantes, institucionalização por regulação pública e, por fim, o estabelecimento de um código de ética formal. Esse modelo, no entanto, se limita a profissões bem estabelecidas, com forte reconhecimento social e jurisdição sobre certos tipos de conhecimento, como advogados, médicos etc. (Abbott, 1988; Butler et al., 2012; Malatesta, 2006).

Nos últimos anos, as tendências pós-industriais acarretaram algumas modificações na força de trabalho, principalmente no que diz respeito à necessidade de trabalhadores especializados dentro e fora das organizações, infringindo assim, os limites tradicionais que denotam status profissional (Evetts, 2011; Gallie, 2013; Noordegraaf, 2011). Em virtude disso, um número crescente de ocupações não seguiu o processo tradicional de profissionalização estabelecido por profissionais legítimos. Contudo, a incapacidade de profissionalizar-se seguindo esses passos tradicionais não impediu o crescimento das ocupações do cuidado (Brint, 2001; Butler et al., 2012).

\section{A profissionalização da atividade de cuidar de idosos no Brasil}

Como se trata de um conceito polissêmico, não existe uma única e global compreensão acerca do "cuidado" e da atividade de cuidar. O care pode assumir distintas conotações em diferentes realidades socioculturais, pois "o cuidar possui uma história que evoluiu ao longo do tempo e induziu práticas distintas em função da forma como foi sendo concebido" (Alves, 2019, p. 2). Isso implica variados direcionamentos para o trabalho de cuidar e sobre cuidadores, a depender do contexto de análise. Neste artigo, partimos do pressuposto que o cuidado e a atividade de cuidar, ou até mesmo "ocupações relacionadas ao cuidado", ainda que recorrentes no cotidiano e que sinalizem diversos significados no Brasil, historicamente estão associados a tarefas praticadas por agentes femininos para assistir pessoas dependentes (Guimarães et al., 2011).

Nesse cenário, o suporte aos idosos, historicamente, tem sido realizado de modo conjuntural ou voluntário, oferecido no próprio domicílio, na comunidade ou em instituições (Batista et al., 2014; Camarano \& Mello, 2010). Até então, os cuidados de longa duração aos idosos eram realizados pelas famílias, amigos e/ou vizinhos, de forma gratuita, configurando-se como informais e como tarefa majoritariamente incumbida às mulheres (Batista et al., 2014; Camarano \& Mello, 2010; Hirata, 2016).

Contudo, algumas mudanças econômicas, sociais e assistenciais no Brasil, como a diminuição da taxa de fecundidade, a constante elevação dos custos de saúde, as mudanças nos modelos assistencialistas e o aumento do número de divórcios e da taxa de envelhecimento populacional provocaram algumas alterações na estrutura familiar, compelindo cada vez mais a inserção de mulheres no mercado de trabalho brasileiro e, assim, reposicionando-as quanto ao papel de cuidadores, que tradicionalmente assumiam (Batista et al., 2014; Camarano \& Mello, 2010; Sorj \& Fontes, 2012). Essa nova configuração demandou a contratação de cuidadores formais que, por sua vez, se apresenta como uma das alternativas no auxílio desse cuidado (Batista et al., 2014). O cuidado formal, portanto, passou a ser realizado em domicílio ou em instituições, prestado pelo Estado ou pelo mercado (Camarano \& Mello, 2010; Camarano \& Mello, 2012). 
O aumento na procura de profissionais do cuidado fez surgir agências especializadas em seleção e encaminhamento, cursos de formação e outras formas de legitimação da atividade de cuidadores de idosos. Desse modo, a imagem do cuidador ganhou força, o que vem sendo assistido há algumas décadas. Esse, por sua vez, se tornou um novo ator político, objeto de propostas de ações e intervenções governamentais e legislativas (Debert \& Oliveira, 2015).

No cenário brasileiro, a discussão sobre os cuidadores formais, pelo Governo Federal, obteve visibilidade em 1998. No entanto, foi em 1999, com a Política Nacional de Saúde do Idoso, que se estabeleceu a definição de cuidador (Batista et al., 2014). Esse é compreendido, portanto, como

uma pessoa, membro ou não da família, que, com ou sem remuneração, cuida do cuidado do idoso
doente ou dependente no exercício das suas atividades diárias, tais como alimentação, higiene
pessoal, medicação de rotina, acompanhamento aos serviços de saúde ou outros serviços
requeridos no cotidiano - por exemplo, ida a bancos ou farmácias -, excluídas as técnicas ou
procedimentos identificados com profissões legalmente estabelecidas, particularmente na área da
enfermagem (Portaria no $1395,1999 \mathrm{~b}$, p. 20).

Nesse mesmo ano foi deliberada a Portaria Interministerial no 5.153/99 (1999a), que concebeu o Programa Nacional de Cuidadores de Idosos (Batista et al., 2014). Essa Portaria recomenda o estabelecimento de protocolos específicos junto às entidades não governamentais e às universidades, com o propósito de capacitar os cuidadores institucionais e domiciliares, familiares e não familiares.

No entanto, a ocupação de cuidador formal só recebeu reconhecimento com a reedição da Classificação Brasileira de Ocupações (CBO) em 2002, por meio do código 5162-10 (Duarte, 2006). A CBO é o dispositivo normalizador de reconhecimento, da nomeação e da codificação dos títulos e características das ocupações do mercado de trabalho brasileiro, cuja finalidade é a identificação dessas. As classificações surgem da associação de práticas similares de emprego ou trabalho (Ministério do Trabalho e Emprego, 2010). Para a CBO, o exercício da função de cuidador requer uma formação em cursos livres com carga horária de 80/160 horas, idade mínima de 18 anos e ensino fundamental completo. $O$ cuidador pode ser um trabalhador assalariado ou autônomo e empreender sua ocupação tanto em domicílios como em instituições cuidadoras de idosos. Seus horários de trabalho podem se dar por revezamento de períodos/turnos ou por tempo integral (Ministério do Trabalho e Emprego, 2010).

Nesse contexto, é relevante pontuar também que existem diferenças quanto às profissões de auxiliares e técnicos de enfermagem e de cuidadores. Os cuidadores podem possuir formação técnica em enfermagem, evidenciando uma simbiose ocupacional. Entretanto, no âmbito das diretrizes do trabalho $(\mathrm{CBO})$ e no próprio movimento organizado da enfermagem (por meio, por exemplo, do Conselho Federal de Enfermagem - COFEN), busca-se assinalar essas diferenças (COFEN, 2010), uma vez que tratam de ocupações distintas e possuem inscrições diferentes na $\mathrm{CBO}$, inclusive.

Além disso, o cuidador deve portar as seguintes competências, a fim de desempenhar suas atividades: a) preparo físico e emocional, empatia, paciência, criatividade, discrição, iniciativa e honestidade; b) demonstrar capacidade de acolhimento, escuta, percepção, adaptação, tomada de decisões, administração do tempo, reconhecimento dos limites pessoais, busca de informações e orientações técnicas; c) respeitar a privacidade dos idosos; d) manter a calma em situações críticas; e, por fim, e) transmitir valores a partir da fala e do próprio exemplo (Ministério do Trabalho e Emprego, 2010).

Contudo, a regulamentação da profissão só é realizada por meio de lei, cuja apreciação é executada pelo Congresso Nacional, pelos Deputados e Senadores, e levada à aprovação do Presidente da República (Ministério do Trabalho e Emprego, 2010). Dessa forma, distintos projetos de lei tentam criar uma lei nacional com vistas à transformação da função de cuidadores em profissão regulamentada. Sendo assim, tramitam na Câmara dos Deputados três projetos de Lei: no 6.966/2006 (2006), no 2.880/2008 (2008) e no 2.178/2011 (2011). Convém ressaltar que 
o projeto de Lei 6.966/2006 foi arquivado na data 25/09/2017 e, por isto, desapensado do projeto de Lei 2.880/2008, o qual permanece em tramitação. Já no Senado Federal, outro projeto de lei referente ao tema, o Projeto de Lei do Senado no 284 de 2011 (2011), foi aprovado nessa instância em novembro de 2012 e encaminhado à Câmara dos Deputados para apreciação, desde então.

Vale destacar ainda que o Senado, em maio de 2019, aprovou o Projeto de Lei no 1.385 C/2007 na Câmara dos Deputados), que buscava regulamentar a profissão de cuidador de idosos, crianças, pessoas com deficiência ou doenças raras; porém, em julho do mesmo ano, o presidente Jair Bolsonaro vetou integralmente o projeto, sob a justificativa de que, ao criar requisitos e condicionantes para a profissão, a lei restringiria o livre exercício profissional. Esse veto total foi mantido pelo Congresso Nacional em outubro de 2019 (Câmara dos Deputados, 2019). Atualmente, outros dois projetos tramitam no Senado, a saber: o Projeto de Lei do Senado, $\mathrm{n}$ 76 de 2020 (2020a), de autoria de Chico Rodrigues, que visa a novamente criar e regulamentar as profissões de cuidador de pessoa idosa, infantil, pessoas com deficiência e com doença rara; e o Projeto de Lei do Senado, no 3242 de 2020 (2020b), proposto pelo senador Flávio Arns, que também busca reconhecer e regulamentar especificamente a profissão do cuidador de idosos, sem impor requisitos ou exigências em relação à ocupação. Tais projetos de lei brasileiros evidenciam, por um lado, a intenção do poder público brasileiro de profissionalização dos cuidadores de idosos e, por outro, a perpetuação da precariedade das políticas públicas voltadas ao cuidado (Batista et al., 2014; Debert \& Oliveira, 2015).

\section{Procedimentos metodológicos}

Considerando o propósito de analisar o discurso produzido pelas empresas do ramo do cuidado no Brasil, adotou-se uma abordagem qualitativa de pesquisa. Além disso, este estudo caracteriza-se como sendo descritivo (Denzin \& Lincoln, 2006).

Realizada em meados do mês de novembro do ano de 2017, a coleta de dados foi empreendida a partir da seleção de discursos que são apresentados em sites de empresas que oferecem a contratação e/ou indicação dos serviços de cuidador profissional. A pesquisa foi feita em sites de empresas que se situam nas cinco regiões do Brasil, a saber: Norte, Nordeste, Centrooeste, Sudeste e Sul. Ao todo, foram 72 sites pesquisados.

No entanto, para a constituição do corpus de análise, priorizou-se a escolha de sites de empresas das regiões sul e sudeste do país, pelo fato de essas regiões apresentarem um maior número de empresas e, principalmente, pela facilidade de acesso ao site dessas empresas e a um corpus consolidado de análise. Os discursos produzidos por empresas nas regiões Norte, Nordeste e Centro-oeste foram incluídos quando encontrados, mas apresentam pouca representatividade considerando as outras regiões.

Nesta pesquisa, o entendimento é de que, por meio de discursos, é possível compreender a produção de sentidos na dinâmica de relações sociais historicamente constituídas e culturalmente localizadas (Spink \& Medrado, 1999). Nesse contexto, com base em Fairclough (2001), o discurso empresarial pode ser compreendido como um tipo específico de linguagem, usado em situações específicas, como é o caso do discurso jornalístico. Porém, vale ressaltar que o conteúdo político e ideológico subjacente ao discurso empresarial busca legitimar a atuação das empresas diante da sociedade e naturalizar e difundir os preceitos da ideologia neoliberal (Irigaray et al., 2016), como será reforçado adiante.

Para a interpretação do material coletado utilizou-se o aparato teórico-metodológico da análise do discurso em sua vertente francesa. Diante do conjunto de discursos selecionados nos sites das empresas, foram realizadas leituras que possibilitaram a identificação de alguns fragmentos discursivos. Especificamente, a análise de tais enunciados discursivos foi empreendida tendo em vista a sistemática de identificação: (i) dos principais aspectos da análise lexical; (ii) dos temas e das figuras (explícitos e implícitos); (iii) dos principais percursos semânticos estruturados a partir dos temas e figuras; (iv) dos aspectos interdiscursivos, isto é, da memória 
discursiva, um conjunto de já ditos, em outro lugar, independentemente, que sustenta todo o dizer (Santos, 2013); (v) dos aspectos da sintaxe discursiva; (vi) dos aspectos refletidos e refratados nos discursos; (vii) das condições de produção dos discursos; (viii) dos principais discursos presentes no texto; (ix) dos aspectos ideológicos defendidos e combatidos nos discursos; (x) da posição do discurso hegemônico em cada um dos textos, em relação aos discursos hegemônicos na sociedade em que eles se situam.

Além disso, durante o processo de busca dos discursos nos sites das empresas, foram selecionadas algumas imagens que foram identificadas como alusivas ao que se pode chamar de estética do cuidado, uma espécie de representação imagética das relações que envolvem o ato de cuidar. Desse modo, procedemos com a análise discursiva do objeto do estudo materializado em imagens e depoimentos (Gregolin, 2007), realizando a interpretação destas imagens levando-se em conta o contexto e/ou os trechos discursivos que àquelas estavam vinculadas, como pode ser visto na seção a seguir, sobre os resultados da pesquisa.

\section{O discurso empresarial oficial brasileiro sobre o profissional e a profissionalização do cuidador}

A partir da análise do corpus de pesquisa, foi possível identificar dois principais percursos semânticos, a saber: o da gestão e o do trabalho.

Nos textos, o percurso semântico da gestão aparece sustentado por um conjunto de temas, figuras e discursos que faz alusão a um processo organizado e sistemático que orienta o cumprimento do objetivo de oferecer os serviços relacionados ao ato de cuidar. Especificamente, a apropriação que o capitalismo empreende em relação ao ato de cuidar é uma noção que se reflete nos discursos sob esse percurso semântico. Por seu turno, no percurso semântico do trabalho, identificam-se temas, figuras e discursos que atuam de modo a constituir corpos e subjetividades de sujeitas e sujeitos que exercem a atividade de cuidar. A ideia da produção de corpos e subjetividades é usada aqui para ressaltar que quem exerce a atividade precisa apresentar determinadas características e condutas, o que evidencia as dinâmicas concretas e simbólicas da profissão do cuidado.

Um discurso que aparece no âmbito do percurso da gestão é o da mercantilização do cuidado, isto é, a ideia de que o cuidar do outro se insere na categoria de mercadoria que pode ser negociada e/ou comprada em um contexto de relações entre ofertantes e consumidores/clientes. Sobre isto, Hirata (2016) relata que a mercantilização do care e a profissionalização desse serviço são especificidades do processo de construção das modalidades do care no Brasil. "Clientes" e "empresa" são alguns dos personagens desse discurso da mercantilização do cuidado, cujos temas discursivos são a segurança, confiança, satisfação, conforto, experiência, qualidade, desenvolvimento, saúde, transparência, excelência, tranquilidade, comodidade. Esses temas cumprem a função de caracterizar o trabalho do cuidado que se compra no mercado. São apresentados a seguir os fragmentos discursivos (1), (2), (3) (04) e (5) que permitiram essa interpretação:

(1) Somos a [Empresa 2], e agradecemos a todos os clientes que nos deram a honra de serem atendidos pela nossa empresa. O nosso objetivo é de encontrar soluções para melhorar a sua vida (EMPRESA 2) (grifo nosso).

(2) Sabemos que escolher a melhor opção de cuidado em saúde para alguém especial é um momento muito importante. Por isso, somos rigorosos em nossos processos de auditoria e controle de qualidade, reforçando a transparência e a excelência técnica dos procedimentos realizados (EMPRESA 11) (grifo nosso). 
(3) Atender a necessidade do mercado oferecendo segurança e conforto ao assistido é a nossa missão, assim como prestar sempre um serviço de elevado padrão de qualidade, garantindo tranquilidade para a família que contrata a prestação do serviço (EMPRESA 13) (grifo nosso).

(4) Temos planos ideais para a demanda de cada cliente. Estamos sempre disponíveis para nos adequar à sua disponibilidade e comodidade. $\mathrm{O}$ cuidado que você deseja no lugar que você precisa (EMPRESA 24) (grifo nosso).

(5) A [Empresa 25] é uma empresa brasileira, criada em 2006, com o objetivo de levar saúde a casa dos nossos clientes e gestão em saúde com a melhor relação custo $\mathbf{x}$ benefício... $\mathrm{O}$ foco da [Empresa 25] consiste na excelência do cuidado domiciliar e por este motivo permanecemos em desenvolvimento constante para atender as necessidades do mercado (EMPRESA 25) (grifo nosso).

O discurso da mercantilização é construído de modo a ressaltar o aspecto produtivo do cuidado, isto é, o cuidado como atividade remunerada e, mais precisamente, um serviço prestado a partir de uma dimensão pública, do mercado em que se configura oferta e demanda, ao invés de uma atividade que comumente se associa ao âmbito da reprodução, do ambiente do privado, do familiar. Considerando esse aspecto, identificamos como a articulação entre as dimensões pública e privada é viabilizada para alinhar-se aos interesses de quem conduz o mercado neste contexto capitalista. As expressões "processos de auditoria", "controle de qualidade", "excelência técnica", "relação custo-benefício", típicas de um contexto empresarial, são aqui utilizadas a fim de demarcar a adequação do ato de cuidar ao mercado, e indicam as condições institucionais e mercadológicas de produção do discurso. Para Debert e Oliveira (2015), tal contexto consiste em conciliar o nicho de mercado à demanda por cuidadores.

Em se tratando dos fragmentos (6) e (7), o discurso da mercantilização do cuidado aparece associado ao tema da velhice:

(6) O envelhecimento é um processo normal e cada vez mais rápido em nossa sociedade. Ele acontece de forma individual e gradativa, respeitando a lei natural da vida. Com o tempo, ocorrem modificações fisiológicas, bioquímicas e psicológicas no organismo de cada indivíduo, e nossa obrigação é respeitá-las e cuidá-las de forma especial. Por razões de saúde ou percalços da vida, algumas pessoas necessitam, em tempos completamente diferentes, de mais cuidados do que outros; cuidados esses que são sempre singulares e especiais para cada indivíduo ...E foi pensando nessa necessidade que a [Empresa 12] surgiu, oferecendo mão de obra com uma das melhores qualificações do mercado e os melhores serviços em cuidado a domicílio... (EMPRESA 12) (grifo nosso).

(7) A terceira idade, também conhecida como melhor idade, é a melhor fase da vida! E o nosso objetivo é ajudar as pessoas a viverem vidas mais saudáveis, mais felizes e mais gratificantes! Mas essa etapa requer certos cuidados e uma atenção especial. E nós sabemos que isso só é possível por meio de um plano de cuidados específico elaborado individualmente para cada cliente. Sendo assim, temos o cuidado em conhecer a história, entender o apoio que a família quer dar para assim analisar e entender como podemos ajudá-los! (EMPRESA 27) (grifo nosso).

Os aspectos relacionados ao envelhecer são apropriados e ressignificados no âmbito de uma oferta de um serviço que se constitui a partir de temas como felicidade, tempo, cuidado, respeito. Um aspecto refratado no discurso (6) pode ser identificado na seleção lexical: "o envelhecimento é um processo normal e cada vez mais rápido em nossa sociedade”. Já no trecho discursivo (7), observa-se a refração linguística em: "a terceira idade, também conhecida como melhor idade, é a melhor fase da vida”. A refração linguística é utilizada a partir de argumentos que, para quem enuncia, sustentam a defesa de um ponto de vista próprio, isto é, que pode ser ou não compartilhado pelas outras pessoas. A interdiscursividade entre os temas implícitos da saúde e do adoecimento é outra estratégia utilizada para reforçar o discurso da necessidade da compra, no caso, compra do serviço de cuidador. Precisamente, no fragmento (7), após a descrição do envelhecimento como sendo "a melhor fase da vida", busca-se demarcar a 
emergência de uma necessidade: "mas essa etapa requer certos cuidados e uma atenção especial". Necessidade esta a ser atendida pelo serviço que a empresa coloca em oferta.

Quem vende o cuidado busca conformar uma justificativa para quem compra, conforme se depreende dos discursos (8) e (9).

(8) Com a correria do dia a dia que vivemos, fica difícil nos lembrarmos de alguns detalhes que podem ser essenciais para o bem estar dos idosos com quem convivemos, como ser dado medicamento na hora certa, atividades estimulantes, alimentação adequada e o mais importante: companhia e atenção. Além da qualificação profissional que nós oferecemos, você estará seguro de que estaremos fazendo o melhor para seu ente querido (EMPRESA 4) (grifo nosso).

(9) Por que contratar um cuidador? Com o passar dos anos a dinâmica da família brasileira vem se modificando, com isso as formas de acompanhamento e cuidados também. A figura do cuidador, muitas vezes atribuída ao familiar que, por vezes, não se encontra adequadamente preparado para essa prática, podendo com isso acarretar processos deletérios no cuidado a pessoa dependente. $\mathrm{O}$ familiar vivencia a sobrecarga física, emocional e socioeconômica, por isso a necessidade de cuidadores treinados e capacitados de acordo com as necessidades do idoso, diante deste novo cenário, a figura do cuidador formal é imprescindível (EMPRESA 45).

No fragmento (08), o tempo é o marcador de um estilo de vida incompatível com o ato de cuidar do outro. Alusiva a esse respeito é a seleção lexical: "Com a correria do dia a dia que vivemos, fica difícil nos lembrarmos de alguns detalhes que podem ser essenciais para o bem estar dos idosos com quem convivemos ....". Outrossim, o tema da qualificação aparece também nos trechos discursivos (8) e (9) como sendo um motivo para a compra dos serviços de cuidador. Especificamente no fragmento discursivo (9), faz-se uso da interdiscursividade para a construção de dois discursos, o da qualificação e o da desqualificação em relação ao exercício do cuidado do outro, discursos representados por dois personagens, a saber, o cuidador profissional ou formal "treinado e capacitado" e, de outro lado, o familiar, despreparado para o desempenho das atividades do cuidado.

Identificamos também o discurso da humanização que é usado para apresentar o trabalho do cuidado que se oferece no mercado. Semelhante discurso, representado nos trechos discursivos (10), (11), (12) e (13), intenta a representação do trabalho do cuidado para além das trocas comerciais e monetárias. Em outras palavras, o que as empresas dizem oferecer não seria somente uma relação mediada pelo dinheiro, mas também pela criação de vínculos afetivos que são sugeridos pelos temas do carinho, atenção, respeito, segurança, dignidade, amor, amizade, dedicação, família, temas estes recorrentes nos fragmentos que seguem.

(10) Nossos cuidadores de idosos são devidamente capacitados e aptos a desenvolverem suas atividades. A atribuição de atividades aos nossos cuidadores será sempre de acordo com a necessidade do cliente conforme previamente combinado na adesão do serviço, segue alguns exemplos: estar sempre ao lado do nosso cliente; ser o amigo perfeito... (EMPRESA 4) (grifo nosso).

(11) Prestamos cuidado com dignidade e respeito (EMPRESA 27) (grifo nosso).

(12) .... [Empresa 28] oferece um trabalho diferenciado, tratando todos os nossos pacientes como extensão de nossa família! (EMPRESA 28) (grifo nosso).

(13) Nossa colaboração maior é no sentido de introduzir técnica e profissionalismo nesse ambiente, sem interferir no principal remédio do tratamento: o calor humano (EMPRESA 18) (grifo nosso).

(14) Nós estamos ligados ao cuidar, e esse cuidar não requer apenas conhecimento, requer também carinho, respeito, atenção e, principalmente, amor no trato com as pessoas. Assim expressamos o nosso modo de trabalhar, especialmente considerando que cuidamos de pessoas nos seus momentos de maior fragilidade, momentos esses em que é importante a garantia da 
dignidade de todos e a transmissão de uma sensação de segurança que eleve a auto-estima da pessoa cuidada (EMPRESA 56) (grifo nosso).

Desse modo, o discurso da humanização que destaca fortemente o compromisso emocional envolvido no trabalho do cuidado que é oferecido pelas empresas pode ser entendido como uma estratégia de posicionamento daquele serviço no mercado e uma tentativa de omitir a relação comercial. Com relação à dimensão afetiva dos cuidados, Batista e Bandeira (2015) consideram a compaixão uma característica do trabalho do cuidado. Para as autoras, a compaixão é entendida como um processo de base fisiológica ancorada na evolução da espécie, porém, tomada de forma consciente e mediada por significados morais e políticos associados a relações de poder durante o trabalho de cuidado.

Ainda na perspectiva da humanização do cuidado, e fazendo uso da figura da "casa", o implícito pressuposto no trecho discursivo (15) é a indicação da diferença que perpassaria o cuidado recebido em outros espaços e oferecido por outros atores, e o cuidado que se (re)produz no ambiente domiciliar e familiar por um profissional capacitado oferecido pelas empresas. Em outros espaços, implicitamente, se evoca a ideia de sociabilidades pouco saudáveis para quem está sendo cuidado, o que representaria, então, uma interpretação sobre um "outro lado do cuidado".

(15) A [Empresa 12] acredita na importância do convívio familiar como auxílio na recuperação de quadros de saúde de idosos. Desta forma, ao invés de uma casa de repouso, você pode optar por contratar um profissional capacitado e supervisionado para atender às necessidades de seu ente querido em seu próprio lar, sem privá-lo de sua rotina diária ou do conforto e comodismo de sua casa (EMPRESA 12) (grifo nosso).

Outro tema que se identifica no discurso da mercantilização do cuidado é o lucro que pode ser obtido neste mercado do cuidado. Esse tema aparece, primordialmente, nos discursos de empresas que pertencem às redes de franquias. O cuidado, assim, é representado como uma oportunidade de negócio, a partir do discurso do empreendedorismo.

(16) Seja um Franqueado [Empresa 9]. Buscamos por empreendedores que se identifiquem com o serviço de Gestão de Pessoas e possuam capacidade financeira para investir neste projeto. Seja um de nossos franqueados e obtenha sucesso abrindo seu próprio negócio, contando com nossa experiência e orientação (EMPRESA 8) (grifo nosso).

(17) O mercado de trabalho é crescente e inesgotável. A franquia [Empresa 37] é a opção ideal pra você participar desse mercado e ainda alcançar seus objetivos pessoais com um negócio que cabe no seu bolso. Se você está procurando abrir um novo negócio ou mesmo profissionalizar sua atuação no mercado de cuidadores de pessoas, nós também podemos ajudá-lo a fazer uma transição correta e lucrativa para a [Empresa 37] (EMPRESA 37) (grifo nosso).

A seleção lexical "o mercado de trabalho é crescente e inesgotável" apresenta-se como um aspecto refratado no fragmento (17). Quem enuncia utiliza-se do apelo a um suposto crescimento do mercado do cuidado para atrair os investidores. Em ambos os trechos discursivos (16) e (17), o empreendedor de sucesso é personagem construído no âmbito do mercado do cuidado. Nesse contexto, fica evidente que tanto o discurso humanizador quanto o de empreendedor de sucesso produzidos por esses discursos empresariais buscam legitimar a atuação dessas empresas perante a sociedade e naturalizar e difundir os preceitos da ideologia neoliberal no país (Irigaray et al., 2016).

Gostaríamos de ressaltar também o conceito de silenciamento neste estudo. Segundo Orlandi (2007), para dizer a partir de uma determinada posição, o sujeito precisa não-dizer outros sentidos. Assim, ao mesmo tempo que emerge a questão do lucro nos discursos analisados, percebe-se um silenciamento em relação aos custos do serviço ofertado ao cliente. Nos fragmentos discursivos, não se faz referência aos preços. Outro silenciamento também recai sobre a questão trabalhista, isto é, não se menciona aspectos que caracterizam os vínculos trabalhistas, 
os direitos dos profissionais etc., o que pode indicar uma tendência de precarização das relações de trabalho no âmbito desse mercado. Para Guimarães et al. (2011), essa precariedade incide devido ao baixo nível de qualificação requerida, do baixo reconhecimento social da competência profissional e da falta de especialização e de formação profissional. Desse modo, os numerosos obstáculos da relação salarial na profissão de cuidador tornam ainda mais urgente a construção de posturas profissionais (Ribault, 2012).

Os temas da especialização e da capacitação sustentam o discurso da profissionalização, isto é, o profissional apresentado pelas empresas não é qualquer profissional, é alguém que possui conhecimentos teóricos e práticos sobre determinado tipo de cuidado que seria específico em relação a determinada doença ou em relação a determinado público-alvo, isto é, crianças, idosos ou gestantes, por exemplo. Nesse sentido, Batista e Bandeira (2015) versam sobre a importância dos conhecimentos e saberes dos cuidadores, haja vista a complexidade envolvida nos modos de operação empregados no cuidado das pessoas. Nos fragmentos discursivos (18) e (19), construídos a partir do percurso semântico do trabalho, este discurso da profissionalização é atravessado pelo tema da enfermagem em uma tentativa de promover a legitimação da atividade de cuidar. Desse modo, o desenvolvimento da profissão do cuidador parece estar relacionado com uma espécie de simbiose ocupacional (Suddaby \& Muzio, 2015).

(18) Para cada caso, dispomos de um profissional capacitado e especializado, prontos para atender qualquer que seja sua necessidade (EMPRESA 4) (grifo nosso).

(19) A [Empresa 13] preza para que todos os seus cuidadores sejam capacitados, treinados e tenham um mínimo de especialização - Técnico em Enfermagem. Podendo assim, transitar em todos os locais com o assistido, sem interferir ou ser diferenciado no dia a dia da família. Nossos cuidadores passam por treinamentos e aperfeiçoamentos periódicos, para que possamos garantir cada vez mais um atendimento de qualidade (EMPRESA 13) (grifo nosso).

Para além da ênfase em especialização e capacitação, aspectos alinhados a uma linguagem do mercado, são elencadas determinadas características que o sujeito deve possuir, características que estão ajustadas ao discurso da humanização, discutido anteriormente.

(20) Todos os nossos colaboradores passam por análise comportamental, em que prezamos por valores e princípios, e também analisamos as características fundamentais de um cuidador de idosos que são: paciência, responsabilidade, sensibilidade, empatia, simpatia, organização e delicadeza (EMPRESA 43) (grifo nosso).

(21) O cuidador é um ser humano de qualidades especiais expressas pelo forte traço de amor à humanidade, solidariedade e doação (EMPRESA 23) (grifo nosso).

No fragmento (20), o pressuposto é que a expressão "análise comportamental" é usada a fim de conferir credibilidade ao processo de seleção dos sujeitos para o exercício do trabalho de cuidar. Tendo em vista os dois fragmentos, podemos afirmar que os aspectos que conformam o imaginário social ligado ao cuidado são refletidos nas características que os cuidadores precisam possuir, quais sejam, "paciência", "responsabilidade", "sensibilidade", "empatia", "simpatia", "organização", "delicadeza", "amor", "solidariedade" e "doação". Tais características se alinham a uma definição dos modos de o sujeito ser e se relacionar no contexto do trabalho do cuidado, sendo implicados, portanto, aos processos de produção de subjetividades para o trabalho. Essas características vão ao encontro das competências necessárias que o cuidador de idosos deve portar para desempenhar suas atividades, segundo a CBO (Ministério do Trabalho e Emprego, 2010).

Além da produção de subjetividades, há ainda uma produção de corpos dos sujeitos envolvidos no trabalho de cuidar, conforme demonstra o fragmento (22).

(22) A cuidadora é contratada para cuidar da pessoa idosa ou pessoas com debilidades temporárias ou permanentes. Muitas famílias ignoram as tarefas que lhe cabe e também cobram 
dela os afazeres domésticos. O perigo é que ao fazer estes serviços, ela deixa de atender a pessoa idosa ou debilitada. Cabe a cuidadora esclarecer ao familiar suas obrigações e atividades inerentes à ocupação, no momento de ser contratada. Como vemos, a cuidadora de idosos tem um trabalho dito domiciliar, não sendo empregada doméstica. Não tem como responsabilidade o cuidado da casa e sim do idoso para quem vai trabalhar (EMPRESA 6) (grifo nosso).

As referências a quem cuida são feitas sempre no feminino, a partir do léxico "cuidadora". Desse modo, quem cuida tem um gênero específico, tem um corpo, mais exatamente, um corpo de mulher. Sobre essa questão, Hirata (2016) fala da veiculação de uma concepção de que o cuidado se refere a uma atividade feminina, concepção esta atrelada ao conceito de divisão sexual do trabalho (Kergoat, 2009).

O percurso semântico do trabalho é construído nos fragmentos discursivos e também nas imagens apresentadas nos sites. O que estas imagens sugerem é que o trabalho de cuidar é representado por uma determinada estética. São corpos femininos, que esboçam uma ideia de limpeza, corpos alinhados, com uma aparência agradável e feliz. Desse modo, a partir da análise dos discursos dessas empresas, fica evidente que as necessidades de formalização e profissionalização do cuidado e a construção da imagem do profissional cuidador, sobretudo de cuidadoras, produzem demandas morais e emocionais para o trabalho de cuidado (Araujo, 2019).

Imagem 1: Site de empresa 33

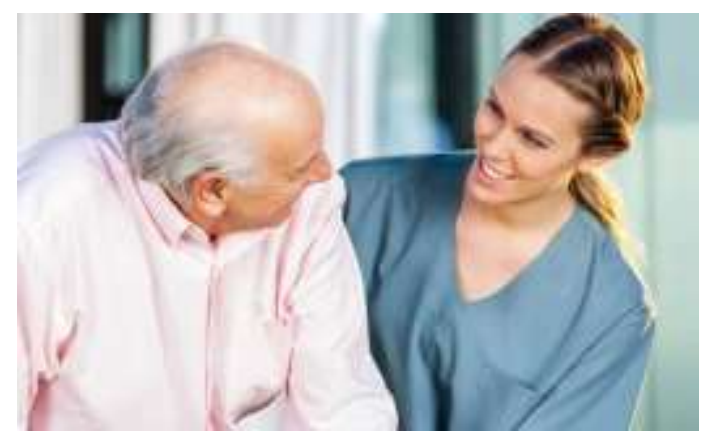

Fonte: Dados da pesquisa
Imagem 2: Site de empresa 42

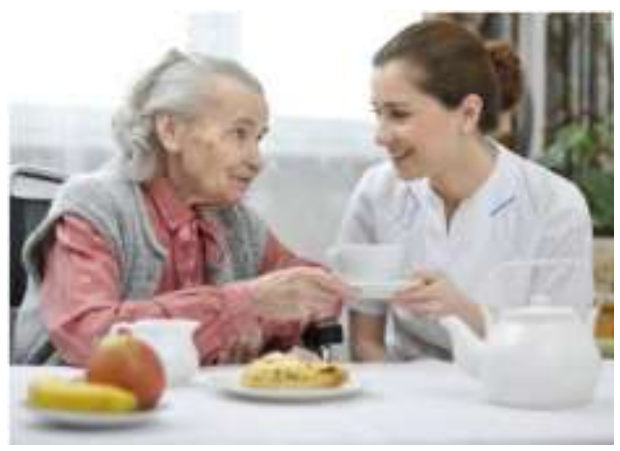

Fonte: Dados da pesquisa

Além do gênero, realiza-se a interpretação sobre a questão da raça pautando as relações desiguais em torno do cuidado. Deparamo-nos com imagens que ilustram negros cuidando de negros, brancos cuidando de brancos e negros cuidando de brancos. Todavia, não foram encontradas imagens de profissionais brancos cuidando de negros, o que nos faz pressupor sobre as influências de uma divisão racial sobre o trabalho do cuidado. Nesse sentido, Sorj e Fontes (2012) elucidam que essa "característica" do care no Brasil implica uma relação de poder que envolve múltiplas dimensões de gênero, classe e cor, que se constituem mutuamente.

Imagem 3: Site de empresa 35

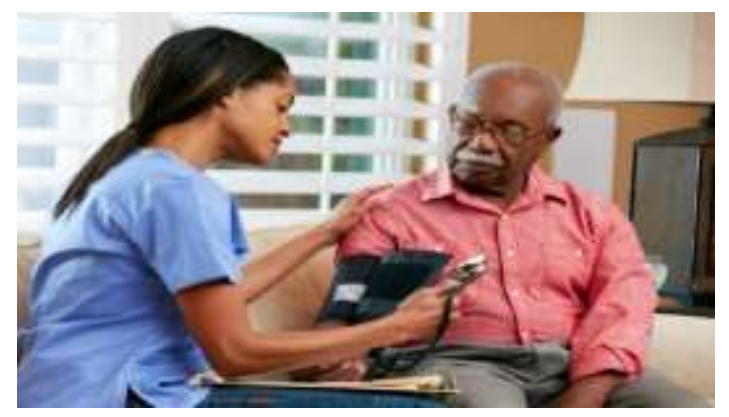

Fonte: Dados da pesquisa
Imagem 4: Site de empresa 37

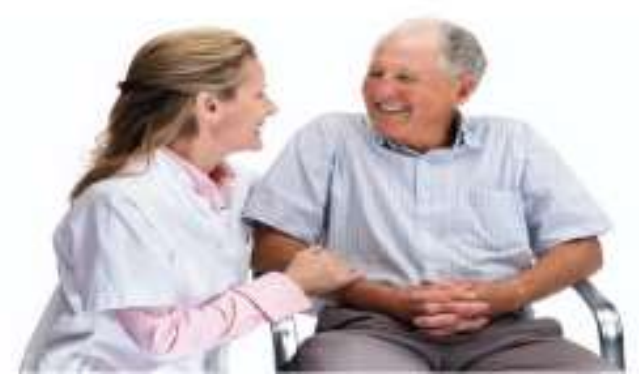

Fonte: Dados da pesquisa 


\section{Considerações Finais}

Esse estudo evidenciou o discurso empresarial oficial brasileiro sobre o profissional e a profissionalização do cuidador. Inicialmente, percebemos que o discurso produzido por essas organizações ora se embasava nos princípios da gestão, ora na esfera do trabalho. No que se refere à gestão, notamos que o discurso apresentado é perpassado pela mercantilização do cuidado, pelas novas formas de organização do trabalho, como, por exemplo, as franquias e pelo lucro obtido nesse mercado do cuidado.

Quanto à esfera do trabalho, identificamos que o discurso proposto pelas empresas se utiliza da humanização, compromisso e emoções do cuidado, numa tentativa de omitir a relação comercial proveniente da dinâmica dessa ocupação e da precarização das relações de trabalho no âmbito desse mercado. Além disso, retrata-se o cuidado como atividade puramente feminina marcada por uma estética de trabalhador limpo, agradável e feliz. No que diz respeito à profissionalização, o discurso apresentado busca legitimar-se a partir de referências às áreas da medicina e da enfermagem. Tal fato pode ser compreendido levando em conta a falta de um espaço profissional a ser ocupado pelo cuidador que delimite com clareza as fronteiras dessa atividade, para que assim não seja confundida com as atividades exercidas por outros profissionais que operam em áreas correlatas. O entendimento é que tal questão reporta-se, portanto, à falta de regulamentação da profissionalização do cuidador no Brasil.

Portanto, foi visto que os percursos semânticos dos princípios da gestão e do trabalho buscam legitimar a atuação desse tipo de empresa e naturalizar a ideologia neoliberal, demonstrando como a lógica de mercado permanece e se reproduz por meio dessas organizações e como tem influenciado o processo de profissionalização de cuidadores no país, ao produzir e especificar corpos e subjetividades dos sujeitos que performam o trabalho de cuidar. Os distintos argumentos advindos dos discursos organizacionais têm respaldo na recente força, visibilidade e expansão que a atividade profissional do cuidador ganhou no Brasil. Semelhante desenvolvimento pode ser explicado pela conjunção do rápido envelhecimento da população brasileira e da entrada em massa das mulheres no mercado de trabalho, uma vez que o encargo do cuidado domiciliar das pessoas idosas, das crianças, dos deficientes e dos doentes tem sido confiado às mulheres (Camarano \& Mello, 2010). Diante disso, o cuidador passa a ser objeto de propostas de ações e intervenções governamentais e legislativas para sua atuação. No entanto, a regulamentação da profissionalização desse tipo de trabalho ainda está em curso, embora a Classificação Brasileira de Ocupações (CBO) inclua tal grupo na sua nomenclatura desde 2002.

Desse modo, os resultados sinalizam a necessidade de refletir sobre as relações construídas entre e a partir dos demais atores envolvidos no processo de profissionalização do cuidador, sejam as pessoas que são cuidadas, bem como os familiares dessas pessoas e até mesmo o próprio cuidador, a fim de gerar discussões aprimoradas e aprofundadas que possam contribuir para o avanço dos processos que delineiam a regulamentação dessa profissão.

Como principal dificuldade deste estudo, podemos citar o processo de operacionalização da análise do discurso francesa em uma grande quantidade de sites distintos e encontrar discursos sistematizados de empresas de cuidado das regiões Norte e Nordeste. Além disso, sugerimos que futuras pesquisas analisem os discursos dos empresários, franqueados, gerentes e supervisores que trabalham nessas organizações, bem como os discursos dos profissionais do cuidado, das pessoas que são cuidadas por esses profissionais e também de seus familiares, a fim de saber como eles percebem a atuação dessas organizações e como enxergam o profissional e a profissionalização do cuidador. Por fim, instigamos que estudos posteriores também aprofundem e problematizem questões relacionadas a gênero e raça na profissão de cuidador. 


\section{Referências}

Abbott, A. (1988). The system of professions: an essay on the division of expert labor. University of Chicago Press.

Alves, C. A. (2019). Cuidado em saúde no Brasil: espaços de criação, lutas e desafios. Cadernos de Saúde Pública, 35 (8), $1-3$.

Araujo, A. B. (2019). Gênero, reciprocidade e mercado no cuidado de idosos. Revista Estudos Feministas, 27(1), 1-13.

Araujo, M. T., Velloso, I. C., Ceci, C., \& Purkis, M. E. (2017). Caregiving for the elderly person: discourses embedded in the brazilian practical guide for the caregiver. Journal of Aging $\mathcal{E}$ Social Policy, 29(5), 444-460.

Barbosa, M. L. (2003). As profissões no Brasil e sua sociologia. Dados - Revista de Ciências Sociais, 46(3), 593-607.

Batista, A. S., \& Bandeira, L. M. (2015). Trabalho de cuidado: um conceito situacional e multidimensional. Revista Brasileira de Ciência Política, (18), 59-80.

Batista, M. P. P., Almeida, M. H. M. D., \& Lancman, S. (2014). Cuidadores formais de idosos: contextualização histórica no cenário brasileiro. Revista Brasileira de Geriatria e Gerontologia, 17(4), 879-885.

Bourdieu, P. (2003). O poder simbólico (6 $6^{\mathrm{a}}$ ed.). Bertrand Brasil.

Brint, S. (2001). Professionals and the knowledge economy: rethinking the theory of post-industrial society. Current Sociology, 49(4), 101-132.

Bucher, S., Chreim, S., Langley, A., \& Reay, T. (2016). Contestation about collaboration: discursive boundary work among professions. Organization Studies, 37(4), 497-522.

Butler, N., Chillas, S., \& Muhr, S. L. (2012). Professions at the margins. Ephemera: Theory $\mathcal{E}$ Politics in Organization, 12(3), 259-272.

Câmara dos Deputados (2019, 02 outubro). Congresso mantém veto total a projeto que regulamentava profissão de cuidador. Câmara Notícias. https:/www.camara.leg.br/noticias/593817-congresso-mantem-veto-total-aprojeto-que-regulamentava-profissao-de-cuidador

Camarano, A. A., \& Mello, J. L. (2010). Introdução. In H. Hirata \& N. A. Guimarães (Orgs). Cuidado e cuidadoras: as várias faces do trabalho do care. Atlas.

Camarano, A. A., \& Mello, J. L. (2012). Cuidados de longa duração para a população idosa: um novo risco social a ser assumido? In H. Hirata, \& N. A. Guimarães (Orgs). Cuidado e cuidadoras: as várias faces do trabalho do care. Atlas.

Cameron, C., \& Moss, P. (2007). Care work in Europe: current understandings and future directions. Routledge.

Chen, Y. M. (2014). Differences in outcomes of caregiver support services for male and female caregivers. Sage Open, $4(3), 1-10$.

Conselho Federal de Enfermagem - COFEN (2010, 28 outubro). Diferença entre cuidador de idoso e auxiliar de enfermagem. Portal COFEN. http://www.cofen.gov.br/diferena-entre-cuidador-de-idoso-e-auxiliar-deenfermagem_5891.html

David, R. J., Sine, Wesley, D., \& Haveman, H. A. (2013). Seizing opportunity in emerging fields: how institutional entrepreneurs legitimated the professional form of management consulting. Organization Science, 24, 356 377.

Debert, G. G., \& Oliveira, A. M. (2015). A profissionalização da atividade de cuidar de idosos no Brasil. Revista Brasileira de Ciência Política, 18, 7-41.

Denzin, N. K., \& Lincoln, Y. S. (2006). O planejamento da pesquisa qualitativa: teorias e abordagens. Artmed.

Diniz, M. (2001). Os donos do saber: profissões e monopólios profissionais. Revan.

Duarte, Y. A. O. (2006). O cuidador no cenário assistencial. Mundo Saúde, 30(1), 37-44.

Evetts, J. (2011). A new professionalism? Challenges and opportunities. Current Sociology, 59(4), 406-422. 
Fairclough, N. (2001). Discurso e mudança social. EdUnB.

Flower, L. (2014). Book Review: Clare L. Stacey the caring self: the work experiences of home care aides. Organization Studies, 35(6), 939-943.

Freidson, E. (1988). Renascimento do profissionalismo: teoria, profecia e política. EdUSP.

Freidson, E. (2001). Professionalism. The third logic. Polity Press \& Blackwell Publishers.

Gallie, D. (2013). Economic crisis, quality of work and social integration. Oxford University Press.

Gregolin, M. (2007). Análise do discurso e mídia: a (re) produção de identidades. Comunicação, mídia e consumo, 4(11), $11-25$.

Guimarães, N. A. (2016). Home and market, love and work, nature and profession: controversies regarding the commodification of care work. Cadernos Pagu, (46), 59-77.

Guimarães, N. A., Hirata, H. S., \& Sugita, K. (2011). Cuidado e cuidadoras: o trabalho de care no Brasil, França e Japão. Sociologia $\mathbb{E}$ antropologia, 1 (1), 151-180.

Gyarmaty K. G. (1975). Professions: an ideology? International Social Science Journal, 27(4), 673-699.

Hirata, H. (2016). O trabalho de cuidado: comparando Brasil, França e Japão. SUR-Revista Internacional de Direitos Humanos, 13(24), 53-64.

Hoffman, G. J., \& Wallace, S. P. (2018). The cost of caring: economic vulnerability, serious emotional distress, and poor health behaviors among paid and unpaid family and friend caregivers. Research on Aging, 40(8), 1-19.

Irigaray, H. A. R., Cunha, G. X., \& Harten, B. A. (2016). Missão organizacional: o que a análise crítica do discurso revela? Cadernos EBAPE.BR, 14(4), 920-933.

Johnson, T. J. (1972). Professions and power. Macmillan.

Kergoat, D. (2009). Divisão sexual do trabalho e as relações sociais de sexo. In H. Hirata, et al. (Orgs.), Dicionário crítico do feminismo (pp. 67-75). EdUNESP.

Lampert, C. D. T., Scortegagna, S. A., \& Grzybovski, D. (2016). Dispositivos legais no trabalho de cuidadores: aplicação em instituições de longa permanência. Revista Eletrônica de Administração, 22 (3), 360-380.

Larson, M. S. (1977). The rise of professionalism: a sociological analysis. University of California Press.

Maestripieri, L. (2016). Professionalization at work: the case of Italian management consultants. Ephemera: Theory $\mathscr{E}$ Politics in Organization, 16(2), 31-52.

Malatesta, M. (2006). Professionisti e gentiluomini. Storia degli ordini professionali nell'Europa moderna. Giulio Einaudi Editore.

Maybud, S. (2015, março). Women and the Future of Work-Taking care of the caregivers. ILO's Work in Progress series. https://www.ilo.org/wcmsp5/groups/public/_.-ed_protect/_.-protrav/... travail/documents/publication/wcms_351297.pdf

Mendonça, O. R. N., Cardoso, R. L., \& Oyadomari, J. C. T. (2012). A profissionalização do contador no Brasil. Revista de Administração e Contabilidade da Unisinos, 9(4), 393-406.

Ministério do Trabalho e Emprego (2010). Classificação Brasileira de Ocupações-CBO-2010 (3ª ed.). Secretaria de Políticas Públicas e Emprego. https:/wp.ufpel.edu.br/observatoriosocial/files/2014/09/CBO-Livro-1.pdf

Moura Jr., P. J., \& Helal, D. H. (2014). Profissionais e profissionalização em tecnologia da informação: Indicativos de controvérsias e conflitos. Cadernos EBAPE, 12(2), 321-338.

Nascimento, L. C. (2007). Profissionalismo: expertise e monopólio no mercado de trabalho. Revista Perspectivas Contemporâneas, 2(1), 105-116.

Neal, M., \& Morgan, J. (2000). The professionalization of everyone? A comparative study of the development of the professions in the United Kingdom and Germany. European Sociological Review, 16(1), 9-26. 
Nogueira, R. M. C. D. P. A., \& Oliveira, J. S. F. (2013). Profissionalismo e Secretariado: história da consolidação da profissão. Revista de Gestão e Secretariado-GeSec, 4(2), 01-24.

Noordegraaf, M. (2011). Risky business: how professionals and professional fields (must) deal with organizational issues. Organization Studies, 32(10), 1349-1371.

Orlandi, E. P. (2007). As formas do silêncio: no movimento dos sentidos. EdUnicamp.

Paiva, K. C. M., \& Melo, M. C. O. L. (2008). Competências, gestão de competências e profissões: perspectivas de pesquisas. Revista de Administração Contemporânea, 12(2), 339-368.

Parsons, T. (1939). The professions and social structure. Social Forces, 17(4), 457-467.

Pereira-Neto, A. F. (1995). The medical profession at issue (1922): a historical and sociological view. Cadernos de Saúde Pública, Rio de Janeiro, 11(4), 600-615.

Portaria Interministerial MS/MPAS n 5.153, de 7 de abril de 1999 (1999a). Institui o Programa Nacional de Cuidadores de Idosos. Ministério da Saúde, Ministério da Previdência e Assistência Social. https:/www.associacaoamigosdagrandeidade.com/wp-content/uploads/filebase/cuidadores-

idosos/BRASIL\%20Implementa\%C3\%83\%C2\%A7\%C3\%83\%C2\%A3o\%20de\%20cuidadores\%20informai s\%282\%29.pdf

Portaria no 1395, de 10 de dezembro de 1999. (1999b) Aprova a Política Nacional de Saúde da Pessoa Idosa. Ministério da Saúde. https://www2.mppa.mp.br/sistemas/gcsubsites/upload/37/Portaria\%20NR\%20139599\%20Politica\%20Nac\%20Saude\%20Idoso.pdf

Projeto de Lei do Senado, no 284 de 2011. (2011). Dispõe sobre o exercício da profissão de cuidador de idoso. Senado Federal https://www25.senado.leg.br/web/atividade/materias/-/materia/100403

Projeto de Lei do Senado no 11 de 2016 (2016). Cria e regulamenta as profissões de Cuidador de Pessoa Idosa, Cuidador Infantil, Cuidador de Pessoa com Deficiência e Cuidador de Pessoa com Doença Rara e dá outras providências. Senado Federal. https://www25.senado.leg.br/web/atividade/materias/-/materia/125798

Projeto de Lei do Senado, n 76 de 2020 (2020a). Cria e regulamenta as profissões de Cuidador de Pessoa Idosa, Cuidador Infantil, Cuidador de Pessoa com Deficiência e Cuidador de Pessoa com Doença Rara e dá outras providências. Senado Federal https://www25.senado.leg.br/web/atividade/materias/-/materia/140481

Projeto de Lei do Senado, no 3242 de 2020 (2020b). Altera a Lei no 10.741, de 1o de outubro de 2003 (Estatuto do Idoso) para prever a figura do Cuidador de Pessoa Idosa. Senado Federal https://www25.senado.leg.br/web/atividade/materias/-/materia/142457

Projeto de Lei no 6.966 de 2006 (2006). Cria a profissão de Cuidador. Câmara dos Deputados. https://www.camara.leg.br/proposicoesWeb/fichadetramitacao?idProposicao=322855

Projeto de Lei no 2.880 de 2008 (2008). Regulamenta a Profissão de Cuidador de Pessoa, delimita o âmbito de atuação, fixa remuneração mínima e dá outras providências. Câmara dos Deputados. https://www.camara.leg.br/proposicoesWeb/fichadetramitacao?idProposicao=384533

Projeto de Lei no 2.178 de 2011 (2011). Dispõe sobre o exercício da profissão de Cuidador. Câmara dos Deputados. https://www.camara.leg.br/proposicoesWeb/fichadetramitacao?idProposicao=518075

Quigley, C. F., \& Hall, A. H. (2016). Taking care: understanding the roles of caregiver and being cared for in a kindergarten classroom. Journal of Early Childhood Research, 14(2), 181-195.

Reay, T., Golden-Biddle, K., \& Germann, K. (2006). Legitimizing a new role: small wins and micro-processes of change. Academy of Management Journal, 49(4), 977-998.

Ribault, T. (2012). Cuidadoras domiciliares: que tipo de profissionalização? In H. Hirata, \& N. A. Guimarães (Orgs.), Cuidado e cuidadoras: as várias faces do trabalho do care (pp. 187-206). Atlas.

Rodrigues, M. L. (2002). Sociologia das profissões (2ª ed.). Celta. 
Santos, A. F. P. R. (2011). Principais abordagens sociológicas para análise das profissões. Revista Brasileira de Informação Bibliográfica em Ciências Sociais, 71(1), 21-43.

Santos, S. S. B. (2013). Pêcheux. In L. A. Oliveira (Org.). Estudos do discurso, (pp. 209-233). Parábola editorial.

Shugrue, N., \& Kellett, K., \& Gruman, C., \& Tomisek, A., \& Straker, J., \& Kunkel, S., \& Robison, J. (2017). Progress and policy opportunities in Family Caregiver Assessment: results from a national survey. Journal of Applied Gerontology, 38(9), 1319-1341.

Smith, A., \& McKie, L. (2009). Researching "Care" in and around the workplace. Sociological Research Online, 14(4), $1-7$.

Sorj, B. (2013). Arenas de cuidado nas interseções entre gênero e classe social no Brasil. Cadernos de Pesquisa, 43(149), 478-491.

Sorj, B., \& Fontes, A. (2012). O care como um regime estratificado: implicações de gênero e classe social. In H. Hirata \& N. A. Guimarães (Orgs.), Cuidado e cuidadoras: as várias faces do trabalho do care. Atlas.

Sotos, F. E., \& García, I. P. (2012). Long-term care, dependence and the third sector. Small Business Economics, 38(3), 321-331.

Spink, M. J., \& Medrado, B. (1999). Produção de sentidos no cotidiano: uma abordagem teórico-metodológica para análise das práticas discursivas. In M. J. Spink (Org.), Práticas discursivas e produção de sentidos no cotidiano: aproximações teóricas e metodológicas. Cortez.

Suddaby, R., \& Muzio, D. (2015). Theoretical approaches to the study of PSFS. In L. Empson, D. Muzio, J. Broschak, \& B. Hinings (Eds.), Oxford handbook of professional services firms. Oxford University Press.

Weber, M. (1999). Economia e sociedade: fundamentos da sociologia compreensiva (vol. 1). EdUnB.

Weber, S. (2003). Profissionalização docente e políticas públicas no Brasil. Educação e Sociedade, 24(85), 1125-1154.

Wilensky, H. L. (1964). The professionalization of everyone? American Journal of Sociology, 70 (2), 137-158.

Endereço para correspondência

claralosilva@hotmail.com
Recebido em: 25/05/2020

Revisado em: 05/01/2021

Aprovado em: 07/01/2021 